\title{
SUSI 62 A ROBUST AND SAFE PARACHUTE UAV WITH LONG FLIGHT TIME AND GOOD PAYLOAD
}

\author{
H.P. Thamm a, b, \\ ${ }^{a}$ FU-Berlin, Geographical Department, Remote Sensing and Geo-Informatics hpthamm@zedat.fu-berlin.de \\ ${ }^{\mathrm{b}}$ Dr. Hans-Peter Thamm. Geo-Technic, Neustr 40, Linz am Rhein, Germany thamm@geo-technic.de
}

Commission I, WG I/V

KEY WORDS: UAV platform, High resolution images, Land cover change, Monitoring, Resource Management

\begin{abstract}
:
In many research areas in the geo-sciences (erosion, land use, land cover change, etc.) or applications (e.g. forest management, mining, land management etc.) there is a demand for remote sensing images of a very high spatial and temporal resolution. Due to the high costs of classic aerial photo campaigns, the use of a UAV is a promising option for obtaining the desired remote sensed information at the time it is needed. However, the UAV must be easy to operate, safe, robust and should have a high payload and long flight time. For that purpose, the parachute UAV SUSI 62 was developed. It consists of a steel frame with a powerful $62 \mathrm{~cm}^{3} 2-$ stroke engine and a parachute wing. The frame can be easily disassembled for transportation or to replace parts. On the frame there is a gimbal mounted sensor carrier where different sensors, standard SLR cameras and/or multi-spectral and thermal sensors can be mounted. Due to the design of the parachute, the SUSI 62 is very easy to control. Two different parachute sizes are available for different wind speed conditions. The SUSI 62 has a payload of up to $8 \mathrm{~kg}$ providing options to use different sensors at the same time or to extend flight duration. The SUSI 62 needs a runway of between $10 \mathrm{~m}$ and $50 \mathrm{~m}$, depending on the wind conditions. The maximum flight speed is approximately $50 \mathrm{~km} / \mathrm{h}$. It can be operated in a wind speed of up to $6 \mathrm{~m} / \mathrm{s}$. The design of the system utilising a parachute UAV makes it comparatively safe as a failure of the electronics or the remote control only results in the UAV coming to the ground at a slow speed. The video signal from the camera, the GPS coordinates and other flight parameters are transmitted to the ground station in real time. An autopilot is available, which guarantees that the area of investigation is covered at the desired resolution and overlap. The robustly designed SUSI 62 has been used successfully in Europe, Africa and Australia for scientific projects and also for agricultural, forestry and industrial applications.
\end{abstract}

\section{INTRODUCTION}

\subsection{Background}

For many tasks in the geo-sciences (erosion, land use, land cover change, etc.) or commercial applications (e.g. forest management, open pit mining, observing power lines, disaster management) there is a need for remote sensing images of a very high spatial and temporal resolution (Thamm \& Judex, 2005; Jütte, 2007; Reidelstuerz et al., 2007; Lei et al., 2009). However, until recently the desired images are often not available when they were most needed. Classical aerial photo campaigns are quite expensive. Additionally, in many areas of the world, especially in developing countries, airplanes as carriers for cameras or other sensors may not be available (Thamm \& Judex, 2006). For optical satellite images with a high spatial resolution cloud cover is a big issue in some parts of the world. Hence UAV's (Unmanned Aerial Vehicles) can be promising tools for obtaining the remote sensing images at the desired temporal and spatial resolution (Everaerts, 2008; Eisenbeiss, 2009; Jütte, 2008). Recent technological improvements in electronics, sensor development and general miniaturisation of components has triggered the development of various types of UAV (Eisenbeiss, 2009). They can be differentiated on the basis of weight, from less than one kilogram to over $150 \mathrm{~kg}$, by their engines, 2-stroke combustion motors or electric motors, or by their type in multi-copter, fixed wing or other. Good overviews of the different systems have been provided by Austin (2010), Eissenbeiss (2009) and Blyenburgh (2010). Each UAV type has its advantages and applications where it can be used successfully. However, the different types may also have disadvantages in regard to limited payload, restricted flight time, dependency on weather conditions, price, fragility and/or a high level of expertise to operate them.

\subsection{Motivation to develop SUSI 62}

To be capable of undertaking daily work under harsh conditions, like mapping of open pit mining, precision agriculture and forest management or other tasks in developing countries, a UAV must meet the following criteria (Thamm \& Judex, 2006):
1. Very robust
2. Easy to operate
3. Easy to maintain
4. High safety in case of failure
5. High payload
6. Long flight time
7. High flight height
8. Relatively slow speed to obtain high quality images, even under poor light conditions
9. Flexibility to mount different types of sensors
10. Easy to transport 
The parachute UAV SUSI 62 was developed to meet these demands. It has been used successfully for various tasks in Europe and Africa, from counting visitors in an urban recreation area in Cologne, observing forest management practices, evaluating the success of land conservation in Africa, mapping the settlement dynamics of migrant villages in Africa and gaining ground truth for the classification of satellite images.

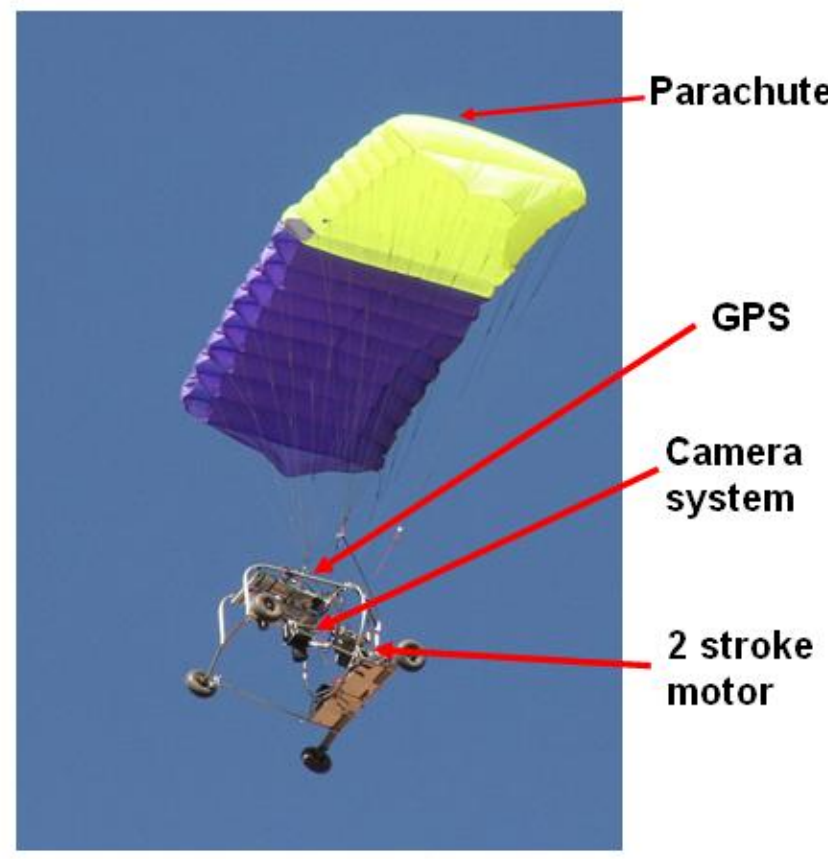

Figure 1. Overview SUSI 62

\section{TECHNICAL DESCRIPTION OF SUSI 62}

\subsection{Body}

2.1.1 Frame: The UAV SUSI 62 consists of two main parts, the frame, made of lightweight steel (used for airplanes) and the parachute. The individual parts of the frame are connected with special alloy junctions, which have a defined breaking threshold. In a crash the junctions break to protect the frame components.

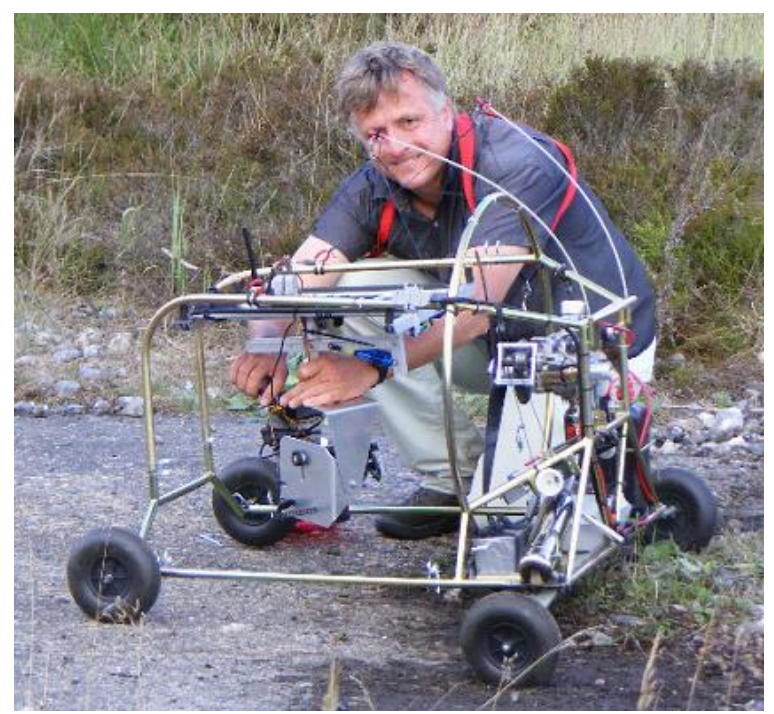

Figure 2. Frame of SUSI 62

The junctions are cheap and easy to replace. The steel frame is weldable. The frame has 4 robust wheels with a carbon / GFK compound suspension system attached to the rear wheels to facilitate smooth landings. The whole frame can be disassembled (Figure 3) and fits into a transport box with all the other parts (except the ground station). The transport box fits into a car (e.g. VW Golf) or an airplane.

2.1.2 Engine: A robust $62 \mathrm{~cm}^{3}$ two-stroke engine (5.5 hp) is attached to the frame with shock-mounts, to limit vibrations to the main frame and the sensor carrier. A pulling 3-blade rotor is used. The engine has an electric starter so that the motor can be switched off during flight, for example to observe animals, and can be started again if needed. This also functions as a safety feature, as if the engine stops for some reason during flight it can be started again.

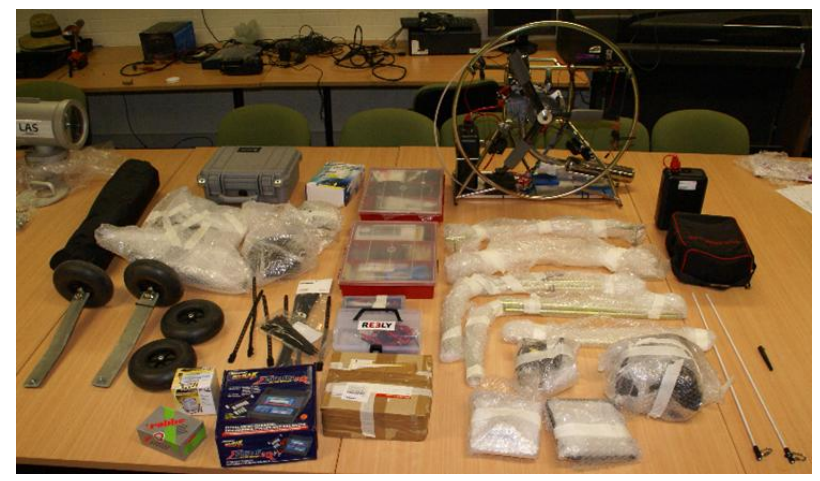

Figure 3. SUSI 62 completely dismantled

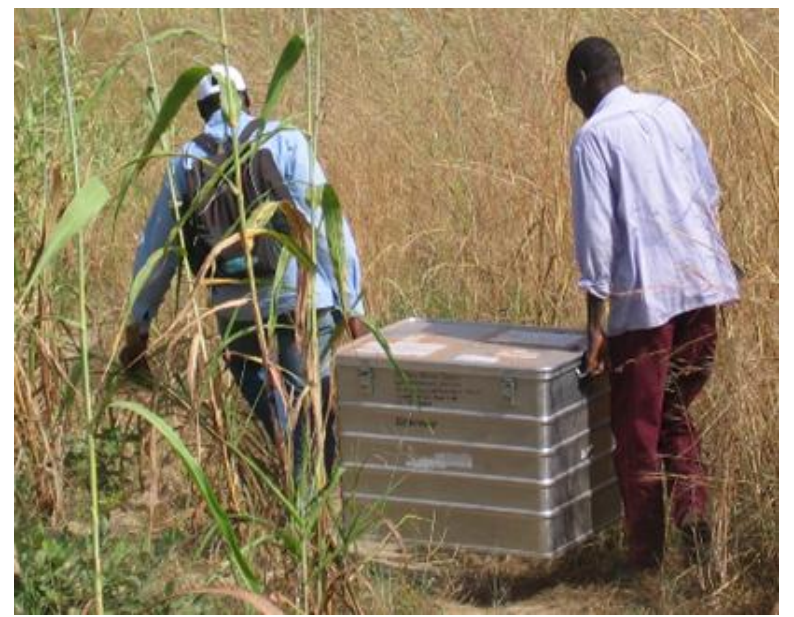

Figure 4. SUSI 62 in transport box 
2.1.3 Payload: The frame supports a gimbal mounted instrument carrier, where different sensors, (such as optical, multi-spectral, thermal or other) can be mounted. The total payload of the UAV is approximately $8 \mathrm{~kg}$. When loaded with batteries and 21 of fuel, more than $5 \mathrm{~kg}$ of payload is available for sensors. Hence it is possible to carry multiple sensors at the same time. The sensors can be operated either manually by the operator via the remote control or automatically via the autopilot after the UAV has reached a pre-defined position. Communication between the remote control / auto-pilot and the sensors is achieved via a special bus system, making it very easy to change sensors.

2.1.4 Transmission of flight parameters: The GPS signal, video stream and other relevant parameters like flight direction, flight height, charge status of the rechargeable batteries, remote control signal strength and others, are transferred in real time to the ground station. This provides the operator a full overview of the condition of the UAV at any time. The range of the data link is presently around $6 \mathrm{~km}$. In the future the use a bi-directional data link with $40 \mathrm{~km}$ range is planned.

\subsection{Parachute}

The parachutes are designed as a "four liner", with two main holding points carrying the weight of the UAV and two flaps for changing direction. There are different parachute sizes available for different wind conditions. A large parachute of $6 \mathrm{~m}^{2}$ area for low wind conditions and a heavy payload, and a smaller parachute of around $4 \mathrm{~m}^{2}$ area for higher wind speed conditions or where greater speed over the ground is desired. The parachute design is very robust and ensures a very low stall speed. The entire system is easy to handle. With approximately two day training, persons are able to operate the system independently. A big advantage is the autonomous stability of the system when it is once up in the air and flying. The system will continue to fly autonomously even with no operator input. That is a big advantage in comparison to most fixed wing UAS.

\subsection{Auto pilot}

An optional auto pilot is available for the SUSI 62. The operator defines the area of investigation, the type of sensor to be used, the focal length of the camera, the desired ground resolution and overlap of the images in the $\mathrm{X}$ and $\mathrm{Y}$ plane, as well as the maximal flight height into a specialised, easy to use software application prior to the flight. The software computes the flight path and the points at which images should be captured or measurements should be made. This flight path is transferred to the auto pilot on board the SUSI 62. Once in flight the auto-pilot can be switched on and the SUSI 62 follows the pre-computed flight paths. Nevertheless, at any time the operator can switch off the auto pilot and steer manually. There is also a "return home" button so that the UAV comes back autonomously to the point where the auto pilot was switched on or to another pre-defined location. The auto pilot system is an own development based on a small industrial micro-controller. As sensors gyros, GPS and a digital compass are utilised. The challenges by the development for the parachute UAS was the comparatively low flight speed, so that the inaccuracy of the GPS can cause problems and the long reaction time between the operation of a flap and the change of direction of the UAS. Due to the low flight speed SUSI 62 can have a deviation of $15 \mathrm{~m}$ left and right to the pre defined flight path if there is stronger wind.
For safety reasons starting and landing have to be performed manually by the operator. It is possible to utilise a landing assistance system which controls the descent speed so that the operator only has to control flight direction.

\subsection{Safety features}

The SUSI 62 incorporates various safety features. If for some reason contact with the operator is lost, the system stops the engine automatically and pulls the landing flaps. This ensures that the system descends at a controlled rate at a comparatively low ground speed. The parachute of the UAV is a big safety feature in itself. As long as the ropes are not damaged (each of the ropes has a breaking strain of $150 \mathrm{~kg}$ ), the system will come down at a reasonably safe speed. In the case of a hard landing or a crash, the breaking alloy junctions of the frame absorb a big proportion of the impact. The sensors are well protected within the frame structure, so even in the event of a rollover the sensors will not get damaged. Of great benefit to the user is the fact that the SUSI 62 is comparatively easy to repair, even out in the field, due to its simple and sturdy design.

\subsection{General flight parameter}

The runway length required for takeoff and landing is dependent upon wind speed, surface roughness and the payload. It ranges from 10 to 50 meter. The maximal flight speed varies between $45 \mathrm{~km} / \mathrm{h}$ with the big parachute and $55 \mathrm{~km} / \mathrm{h}$ with the small parachute. The comparatively low speed over the ground enables a comparatively long exposure time and a good image quality to be captured. But on the other hand that limits the wind conditions where SUSI 62 can be operated. For safety reasons the SUSI 62 should not be used in wind speeds of more than $6 \mathrm{~m} / \mathrm{s}$.

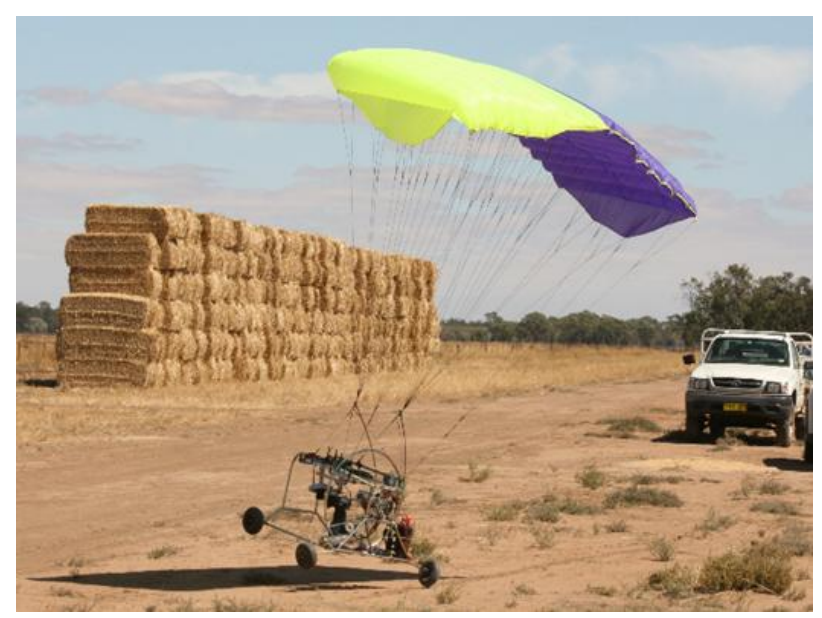

Figure 5. SUSI 62 taking off 


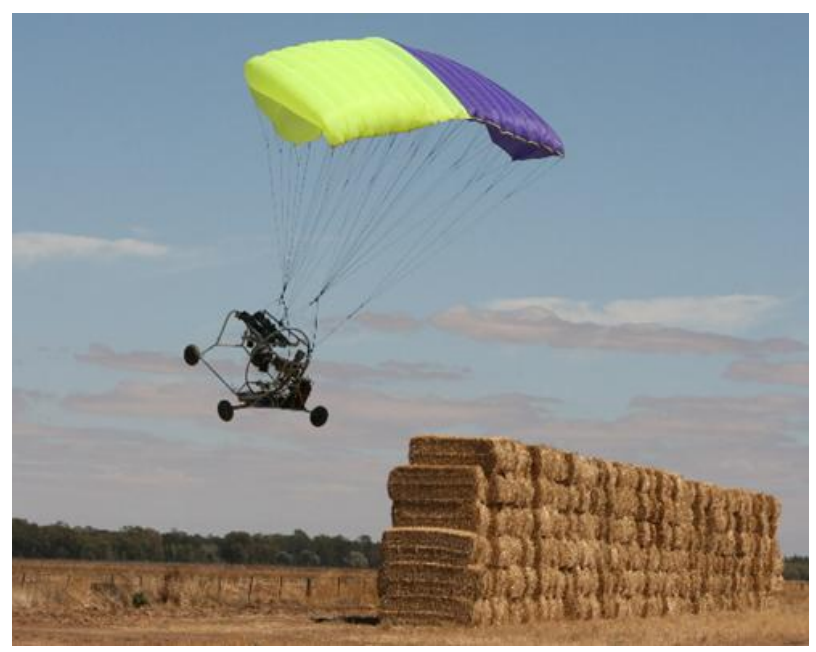

Figure 6. SUSI 62 soon after takeoff

In tests in Africa flight heights of more than $3500 \mathrm{~m}$ above sea level have been reached. The operation radius is a function of the strength of the radio signal of the remote control. German laws limit the operation radius. In practice an operation radius of ca. $2.0 \mathrm{~km}-2.5 \mathrm{~km}$ is used. For special applications it is possible to enlarge the operation radius.

\subsection{Sensors}

A big advantage of the SUSI 62 is the comparative ease of attaching different sensors without needing to recalibrate flight parameters. The intelligent bus system ensures that the control signals for every sensor are transmitted correctly. The SUSI 62 has been flown using a range of sensors. For optical sensors mid-range SLR cameras (e.g. Nikon 300 D), or high end consumer cameras (e.g. Canon D5 Mark II) can be used. Currently testing is being conducted using a 60 Megapixel Hasselblad mid format camera. Specially designed robust multispectral cameras have been used successfully also. Surface temperatures have been captured using robust thermal cameras from Flir. If required, multiple sensors can be mounted, as long as the combined weight doesn't exceed $5.5 \mathrm{~kg}$ and their physical size is not problematic. Many interesting tests are being undertaken on an ongoing basis.

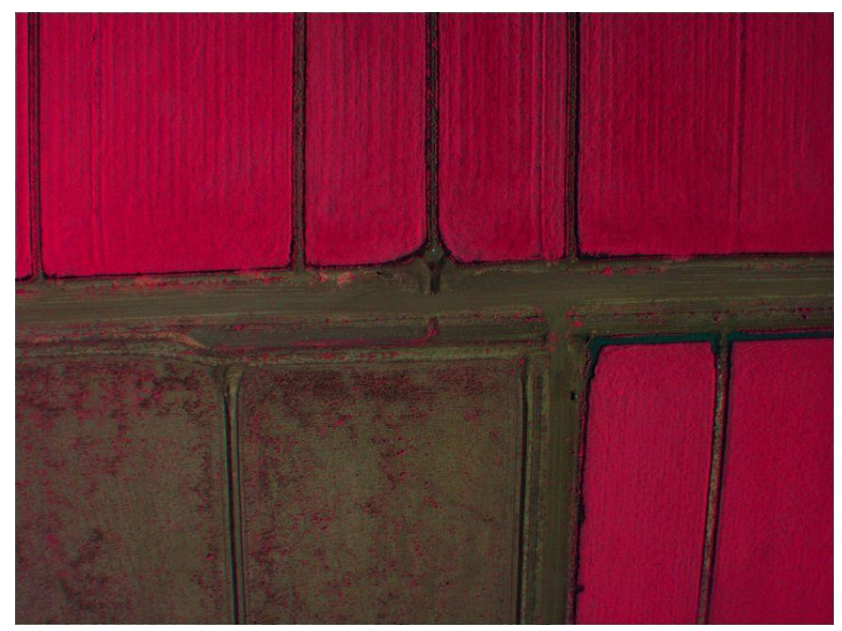

Figure 6. Multi-spectral image of rice fields taken with SUSI 62 (NSW Australia)

\subsection{Long term experiences}

Some SUSI 62 having now more than 600 hours of flight so there are some experiences. The design of the parachute is very save. Only one time SUSI 62 came down uncontrollable was she flew in a dust devil at midday and the parachute got twisted around the ropes and didn't unfold anymore. But even then only the junctions braked but the sensor was not damaged. Sometimes there had been problems with the quality of the fuel in Africa, so that the engine stopped. Then it was often possible to start the engine again in the air. But even in the few cases where it was not possible to start the engine again SUSI 62 came down without getting damaged, or if it his trees, it was possible to repair the parachute and continue the campaign. In an older version there was a problem with the cables to the servos causing problems. But this problem is fixed since 2010 . The most problems were caused by operators which forgot to fill up fuel, don't recharge the batteries or try to fly if the weather conditions are not suitable (too much wind). Problems turned up as well when the runway for start was not suitable (holes, too high vegetation, adjacent trees) or if operators didn't land SUSI 62 facing the wind. Very important is to follow strictly the owner manual and control the proper assembly of SUSI 62 according to the checklist. In the whole period no sensor got damaged by an accident. Only one older camera with retractable lenses got jammed by dust in the semi-dessert of West-Africa.

\subsection{Comparison of SUSI 62 with other UAS systems}

Advantageous is the high operation safety of SUSI 62 (coming down with comparatively low speed in case of loss of control), the short learning time to operate the system, the robust design which stands some rough handling, the possibility to repair it under field conditions, the small pack size, the high payload, the long flight time and flight height, the possibility to operate different sensors at the same time, the possibility to change sensors without the need of new calibration of flight parameter and the low speed which reduces problems with in-motion unsharpness of the image.

Disadvantageous is the need of a runway for start and landing, the higher dependency on weather conditions (wind $<6 \mathrm{~m} / \mathrm{s}$ ), the noise of the 2-stroke engine and the slightly lower accuracy of the auto pilot, a faster system is not so much affected by wind, the more complex process of getting flight permits in some countries due to the weight over $5 \mathrm{~kg}$ and the two stroke engine.

\section{APPLICATIONS}

The SUSI 62 has been used successfully for the following tasks:

1. Mapping building measures: Utilising ortho-photos to document the progress of building activities.

2. Mapping damage caused to plantations by game animals: Using the UAV a forester can map the extent of damage in less than one hour.

3. Monitoring illegal wood harvesting: This was performed in Germany and some West African countries. Because the SUSI 62 can be mobilised very quickly, the images are soon available to be used as evidence.

4. Mapping building measures: Utilising ortho-photos to document the progress of building activities.

5. models with high spatial resolution have been derived. Mapping building measures: Utilising ortho-photos to document the progress of building activities. 


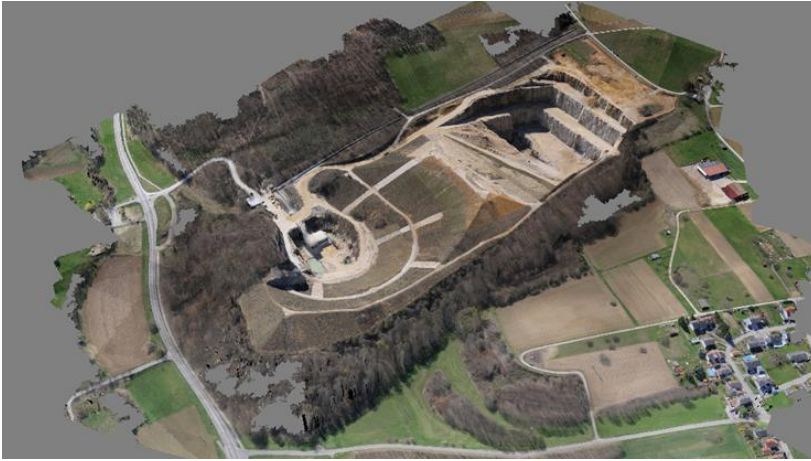

Figure 7. Automatically generated DSM (digital surface model) of an open pit mine with draped ortho-photo created from ca. 300 images taken with the SUSI 62

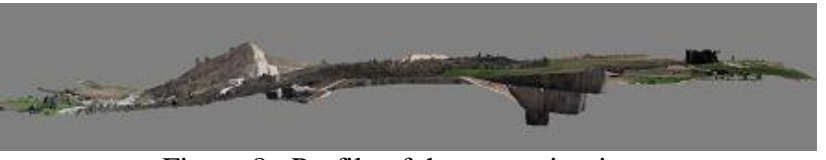

Figure 8. Profile of the open pit mine.

6. Mapping damage caused to plantations by game animals: Using the UAV a forester can map the extent of damage in less than one hour. Mapping open pit mines for management purposes and environmental auditing: orthophotos and digital elevation

7. Mapping building measures: Utilising ortho-photos to document the progress of building activities.

8. Mapping damage caused to plantations by game animals: Using the UAV a forester can map the extent of damage in less than one hour.

9. Mapping surface temperatures for irrigation management in Australia: In this case the SUSI 62 was equipped with optical, thermal and multi-spectral cameras. When water stressed, plants close their stomata with the surface temperature of the leaf increasing by more than 5 degrees Kelvin within 20 minutes. This can be mapped with the thermal camera on the SUSI 62. The information captured was combined with data from climate measurement stations and entered into a model used to determine the efficient use of irrigation water.

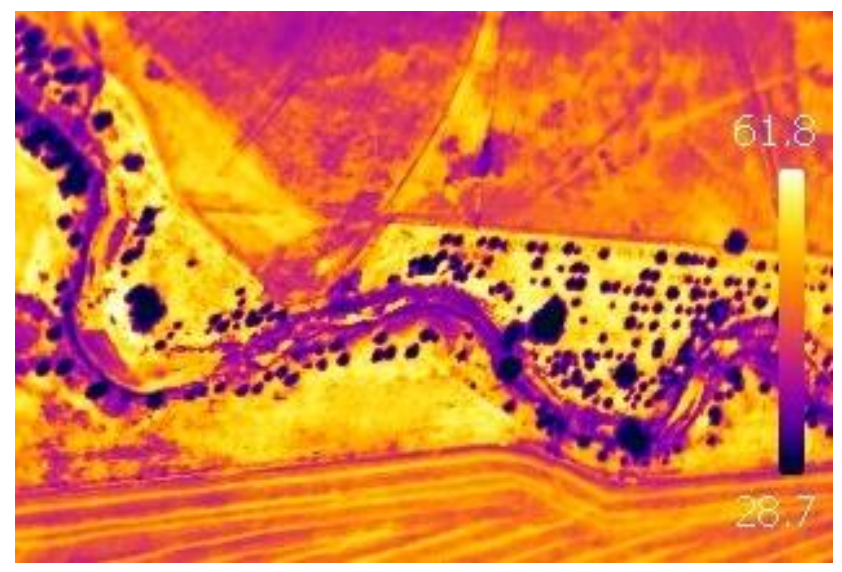

Figure 9. Image of surface temperature taken with SUSI 62 (NSW Australia)

10. Monitoring illegal wood harvesting: This was performed in Germany and some West African countries. Because the
SUSI 62 can be mobilised very quickly, the images are soon available to be used as evidence.

11. Evaluation of erosion control measures: With the SUSI 62 different techniques to stop / minimise erosion were evaluated with a time series of ortho-photos, (i.e. before the rainy season / after the rainy season). By deriving high precision digital elevation models it was possible to estimate the loss of arable soil.

12. Evaluation of land management measures: Development agencies are implementing land conservation and land management measures at significant cost. However evaluating and quantifying the success of the measures using only ground campaigns is expensive and inefficient. Using aerial photos from the SUSI 62 the success of the measures can be evaluated objectively. The SUSI 62's wide range, long flight period and large payload make it possible to assess large areas cheaply.

13. Monitoring animal tracks in national parks: In the Penjari National Park in north-west Benin, tracks of hippopotami have been mapped using the SUSI 62 . The tracks mostly follow the lowest points of the relief.

14. Monitoring visitor behaviour in different recreation and national parks: For example in an urban recreation park in Cologne the spatial and temporal distribution of visitors has been mapped. This provided information about how many people stay on the paths, where people like to rest and so on.

15. Mapping of settlement dynamics: In developing countries with highly dynamic settlements, the SUSI 62 has proved a reliable and comparatively cheap tool to create time series images for documenting settlement dynamics. Base data was created to allow for sustainable settlement planning. In addition the images can be used for the planning, design and implementation of infrastructure (roads, water supply and electric power supply).
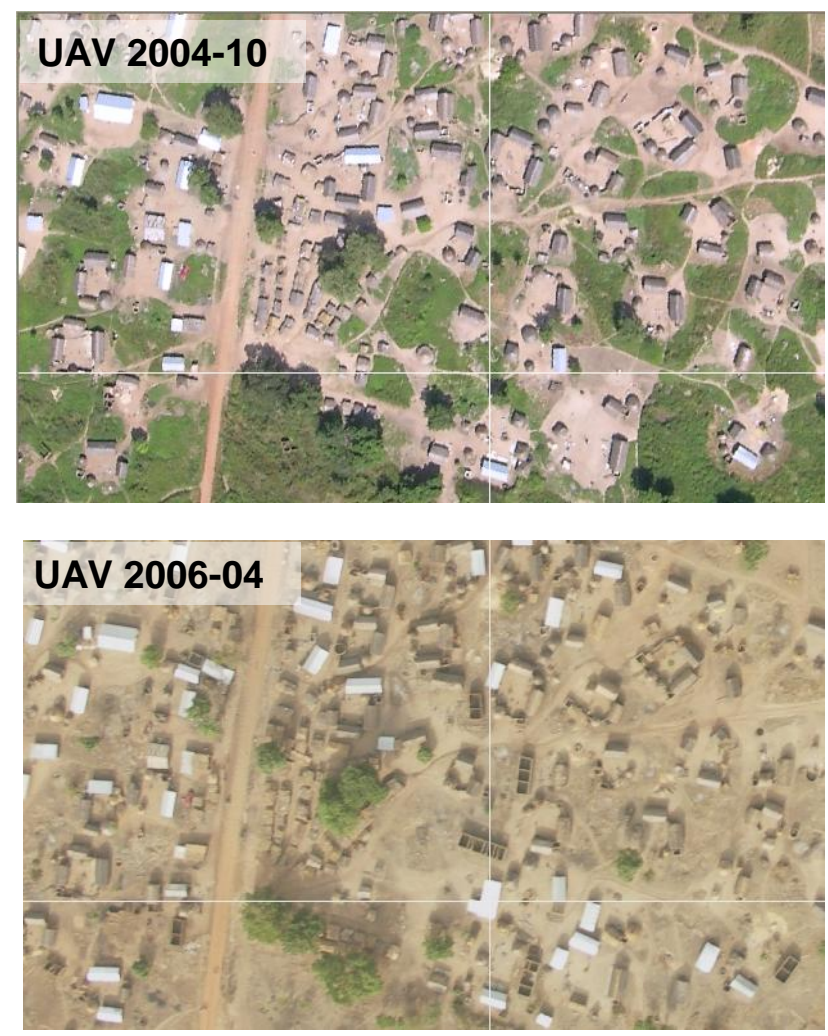


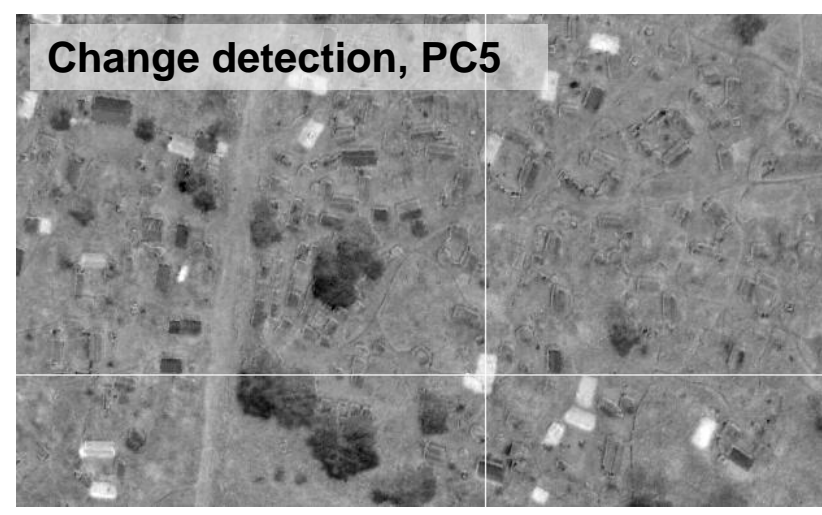

Figure 10. Monitoring settlement dynamics between October 2004 and February 2006 in a migrant village, Kpawa, in Central Benin, West-Africa, with a parachute UAV

The SUSI 62 has also been applied successfully to undertake many other tasks.

\section{SUMMARY}

The SUSI 62 was designed as a robust and safe UAV with a large payload and long flight time for day to day applications. Its capability to operate different sensors (e.g. optical, multi spectral and thermal) at the same time and the ease of swapping sensors offers fascinating options for research and commercial applications. The auto pilot guarantees that the area of investigation is covered completely with the desired overlap and ground resolution. As well time series images with a consistent geometry can be created. This facilitates reliable change detection. The possibility to derive digital elevation models in a very high spatial resolution out of the photos of the SUSI 62 offers interesting possibilities in many fields of research and in real world applications.

The SUSI 62 has been applied successfully in many different projects in Europe and especially under harsh conditions in developing countries. The sturdy design leads to a very good flight time to maintenance relationship. It is comparatively easy to operate, avoiding the constraint that only high skilled experts can use it. In combination with the high system safety and the very interesting TOC (Total Cost of Ownership), the SUSI 62 prooves to be an interesting option for many fields of application.

\section{REFERENCES}

Austin, R., 2010. Unmanned Aircraft Systems. UAVS Design, Development and Deployment. John Wiley \& Son, Hoboken, Chichester.

Blyenburgh, P. van, 2010. Unmanned Aircraft Systems, The Global Perspective 2011/2012, Blyenburgh \& Co., Paris.

Corbane, C., Raclot, D., Jacob, F., Albergel, J., Andrieux, P., 2008. Remote sensing of soil surface characteristics from a multiscale classification approach. Catena 75 (3), 308-318.

Eisenbeiss, H., 2009. UAV Photogrammetry. Dissertation, ETH NO. 18515, Zürich.

Everaerts, J., 2008. The Use of Unmanned Aerial Vehicles (UAVS) for Remote Sensing and Mapping, The International
Archives of the Photogrammetry, Remote Sensing and Spatial Information Sciences, ISPRS Congress, Beijing, China, XXXVII. Part B1, 1187-1192.

Grenzdörffer, G., Engel, A. and Teichert, B., 2008b. The Photogrammetric Potential of Low-Cost UAVS in Forestry and Agriculture, In: The International Archives of the Photogrammetry, Remote Sensing and Spatial Information Sciences, ISPRS Congress, Beijing, China, XXXVII. Part B1, 1207-1213.

Jütte, K., 2007. Innovative Methoden der Überwachung der Kiefergroßschädlinge in Mecklenburg-Vorpommern, Höppner, K., Land Brandenburg, Aktuelle Aspekte zur Bewirtschaftung und Ökologie der Kiefer im nordostdeutschen Tiefland, 1-38.

Jütte, K., 2008. Vergleich verschiedener low-cost Luftbildaufnahmesysteme sowie Einsatz von Drohnen: Grenzen und Möglichkeiten, In: Bayerische Landesanstalt für Wald und Forstwirtschaft Der gepixelte Wald - Fachtagung zur Forstlichen Fernerkundung.

Lei, Y.; Zhiyang, G. and Yini, D., 2009. A UAV Remote Sensing System: Design and Tests, Springer, Heidelberg, New York.

Reidelstuerz, P.; Link, J.; Graeff, S. and Claupein, W., 2007. UAV (unmanned aerial vehicles) für Präzisionslandwirtschaft. 13. Workshop Computer-Bildanalyse in der Landwirtschaft \& 4. Workshop Precision Farming, In: Bornimer Agrartechnische Berichte, 61, 75-84.

Thamm, H. P. and Judex, M., 2006. The "Low cost drone" - An interesting tool for process monitoring in a high spatial and temporal resolution, In: The International Archives of the Photogrammetry, Remote Sensing and Spatial Information Sciences, ISPRS Commission VII Mid-term Symposium "Remote Sensing: From Pixels to Processes", Enschede, the Netherlands, XXXVI part 7, 140-144.

Thamm, H.-P. and Judex, M, 2005. Einsatz einer kleinen Drohne für hoch aufgelöste Fernerkundung. In: Strobl, J., Blaschke, T. \& G. Griesebner (Hrsg): Angewandte Geoinformatik 2005. Beiträge zum 17. AGIT Symposium, Salzburg, 722-729.

Vericat, D., Brasington, J., Wheaton, J., and Cowie, M., 2008: Accuracy Assessment of Aerial Photographs Acquired using Lighter-Than-Air Blimps: Low-Cost Tools for Monitoring Fluvial Systems. River Research and Applications. DOI: 10.1002/rra.1198. 